\title{
The pathology of cornea in Tangier disease (familial high density lipoprotein deficiency)
}

\author{
A F Winder, R Alexander, A Garner, D Johnston, D Vallance, G McCreanor, J Frohlich
}

\begin{abstract}
Aims-To clarify the underlying causes of corneal opacification in Tangier disease. Methods-Both corneas were removed at death from a 62 year old man with Tangier disease, and were examined by direct and transmission electron microscopy, histochemistry, biochemical analysis by thinlayer and gas-liquid chromatography after extraction, and by differential scanning calorimetry.

Results-Membranous inclusions in the stroma were seen on transmission electron microscopy. Direct analysis confirmed enrichment with phospholipids and cholesterol, with acyl patterns and proportions as ester broadly similar to those of normal cornea. Tangier cornea showed major thermotropic phase transitions in the range $28-37^{\circ} \mathrm{C}$, peak $30-33^{\circ} \mathrm{C}$, extending above profiles of normal clear cornea and without the complexity of those seen with cornea with heavy arcus involvement.

Conclusions-Lipid accumulation underlies corneal opacification in Tangier disease. The excess material is mainly phospholipid and cholesterol esters. As at other sites which are below body core temperature, notably tonsil, accumulation may be enhanced by local impaired mobilisation of material as the phase transitions of the excess lipid present extend above ambient corneal temperatures.

(f Clin Pathol 1996;49:407-410)
\end{abstract}

Keywords: Tangier disease, high density lipoprotein, differential scanning calorimetry.

Tangier disease is a rare autosomal recessive disorder of unknown aetiology but which may involve defective intracellular lipid/lipoprotein trafficking and rapid catabolism of immature high density lipoprotein (HDL). ${ }^{1-4}$ A two-step model of cholesterol efflux from cells has been proposed, with Tangier disease involving a defect in the first step of lipidation of apolipoprotein A-I (apo A-I) by phospholipid; this complex is necessary to act as receptor in the second step for transfer of cholesterol ester. ${ }^{5}$ Normal HDL is absent from plasma, generally with apo A-I $<1 \%$ and apo A-II $<10 \%$ of normal concentrations, but of apparently normal structure. The massive accumulation of lipid and particularly cholesteryl esters at various body sites has been presumed also to be the basis of corneal opacification. This is common in Tangier disease and arises in other disorders of HDL metabolism with impaired cholesterol esterification or transport, or both, including familial lecithin cholesterol acyltransferase (LCAT) deficiency and Fish-eye disease, for which the extent and pattern of lipid accumulation has been confirmed by direct corneal analysis. ${ }^{6-8}$

This first direct structural and biochemical analysis of cornea in Tangier disease has confirmed that lipid accumulation, particularly of esterified cholesterol and phospholipid, is the basis for the corneal opacification characteristic of this disorder. Lipid accumulation in Tangier disease seems particularly evident in cooler body areas, notably tonsils exposed to airflow, and also in some reports in the exposed medial and lateral quadrants of the cornea. ${ }^{910} \mathrm{Ac}-$ cumulation of or impaired mobilisation of lipid in various body compartments may reflect relations between thermotropic characteristics of that material and ambient temperature, for which the cornea may be an informative model. ${ }^{112}$ Corneal and scleral samples from a patient with Tangier disease were therefore also examined by differential scanning calorimetry, with further data from unselected but age matched, time expired cornea bank samples with and without macroscopic corneal arcus. The results also further support the proposal that temperature relations may influence lipid accumulation and mobilisation in cornea, and at body sites in general. ${ }^{1213}$

\section{Methods}

\section{CASE REPORT}

The Canadian male patient of British ancestry and from a consanguineous first cousin marriage died aged 62 years, having undergone splenectomy when aged 38 years, tonsillectomy in childhood and enlargement of nose and earlobes in his late 40 's. ${ }^{14} \mathrm{~A}$ liver biopsy specimen taken at cholecystectomy showed lipid accumulation with foam cells. On presentation to lipid specialists aged 56 years, the patient had some yellow streaking of the pharynx and neurological deficit. Tissue, plasma and cellular observations were in accord with a diagnosis of Tangier disease: in life, deficiency of HDL in plasma was severe with HDL cholesterol $<0.1 \mathrm{mmol} / 1$, apo A-I $27 \mathrm{mg} / \mathrm{dl}^{14}$ In his later years he had also suffered chronic keratitis with some ulceration and this or the late presentation and diagnosis may be why the corneal opacification, as shown in fig 1 , was not obviously enhanced in the 3 o'clock and 9 o'clock quadrants, as has been described for younger patients with earlier stage Tangier disease. ${ }^{9}$

PREPARATION OF CORNEAL SAMPLES

Corneas removed postmortem were stored and then transported at $-20^{\circ} \mathrm{C}$, and later re-dissected into central buttons and outer corneo-

Trust and School of

Medicine,

(University of London)

London NW3 2QG.

Accepted for publication 20 February 1996 


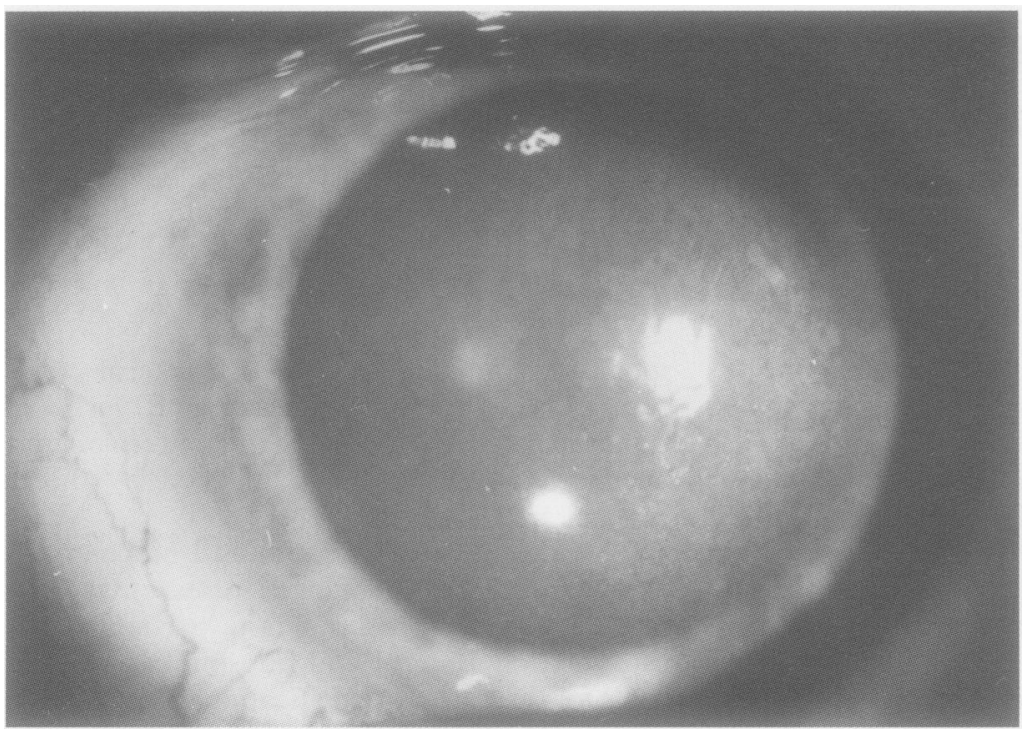

Figure 1 Visual appearance in life of the cornea of a male patient with Tangier disease who died aged 62 years. The patient also had keratitis in later life.

scleral rings with removal of attached vascular elements. Similar corneal samples with and without heavy corneal arcus were prepared from generally age matched, fresh, but time expired normal eyebank corneal material. All corneal samples were then stored at $-20^{\circ} \mathrm{C}$ in tubes flushed with nitrogen, pending further analysis. Prior to biochemical analysis, samples were stored overnight in a vacuum dessicator to ensure dryness.

\section{MICROSCOPY AND HISTOCHEMISTRY}

This was carried out on sections by adding stain at room temperature and then raising stain temperature to $37^{\circ} \mathrm{C}$; on frozen sections; and on paraffin wax embedded material, in view of the potential loss of lipid and particularly cholesterol oleate during preparation. Transmission electron microscopy was also carried out on glutaraldehyde fixed material. The histochemical procedures applied and their specificities are given in table 1 .

\section{BIOCHEMICAL ANALYSIS}

Lipid was extracted by chopping material with a blade and then grinding it with a Dounce allglass hand-held homogeniser in chloroform/ methanol 2:1 (v/v) as previously undertaken in the analysis of LCAT cornea. ${ }^{8}$ For interpretation we have drawn comparisons with our previous data on detailed biochemical analysis of normal-that is, non-Tangier, and pathological cornea, ${ }^{6-815}$ but one or two normal age matched corneas as specified were also put through the extraction procedures as internal standards.

Table 1 Histochemical procedures applied and their specificities

\begin{tabular}{ll}
\hline Histochemical procedure & Specificity \\
\hline Bromine/oil red O & General screen for lipid \\
Oil red O & Neutral fat/phospholipid \\
Okamoto & Chol/chol esters (FC/CE) \\
Digitonin/acetone/Okamoto & FC stains, CE extracted \\
Filipin & FC fluorescence \\
Otan & FC, CE, phospholipid \\
Perchloric acid/naphthoquinone/PAN & FC, CE \\
Digitonin/acetone/PAN & FC stains, CE extracted \\
\hline
\end{tabular}

\section{Thin-layer chromatography}

Extracts of Tangier corneas and two normal corneas were analysed by silica gel thin-layer chromatography (TLC) in hexane/diethyl ether/ acetic acid 80/20/1 (v/v). Identification and quantitation of components, and of the proportion of cholesterol in ester form, was carried out by densitometry against reference standards, with visualisation by a charring procedure applying sulphuric acid/methanol/manganese chloride and heating at $110^{\circ} \mathrm{C}$ for 30 minutes. $^{16}$

Extraction, methylation and gas chromatographic analysis of fatty acids

Dessicator dried aliquots of $5 \mathrm{mg}$ Tangier corneal button and $30 \mathrm{mg}$ normal cornea with arcus were homogenised as above, followed by hydrolysis, extraction, saponification, and methylation, with analysis of the methyl esters and standard material on a Hewlett Packard 5890II gas chromatograph with a flame ionisation detector.

\section{DIFFERENTIAL SCANNING CALORIMETRY}

Samples analysed were a second $5 \mathrm{mg}$ Tangier central corneal button, an $11 \mathrm{mg}$ normal central corneal button, and a $38 \mathrm{mg}$ sample of peripheral normal cornea with heavy corneal arcus. Analysis was carried out with a Perkin Elmer 7 Series Thermal Analysis System over the range $15-42^{\circ} \mathrm{C}$ and at a heating/cooling rate of $2.5^{\circ} \mathrm{C} /$ minute. Samples were allowed to warm to room temperature from $-20^{\circ} \mathrm{C}$ and scanned: cooling runs back to $15^{\circ} \mathrm{C}$ and repeat scans were also recorded, without re-freezing.

\section{Results}

\section{MICROSCOPY AND HISTOCHEMISTRY}

The overall conclusion from direct histology and histochemistry, including immediate visualisation of material stained at $37^{\circ} \mathrm{C}$, was that the Tangier tissue was disrupted, with vacuoles but little specific staining for excess lipid. Transmission electron microscopy, however, revealed numerous membranous myelin-like lamellar bodies in the corneal stroma, periodicity $6.06 \mathrm{nM}$, apparent gap $3 \mathrm{nM}$, consistent with lipid involvement and phospholipid excess (fig 2).

\section{BIOCHEMICAL ANALYSIS}

Scanning densitometry and area quantitation of thin-layer chromatographs showed that in comparison with a reference normal central cornea and our previous observations, Tangier central cornea was enriched with phospholipids and with cholesterol, of which $62-3 \%$ was present in an esterified form as determined by duplicate assay. Tangier corneoscleral (outer) region showed similar enrichment, with 55$63 \%$ of cholesterol in ester form, $66 \%$ as ester in reference normal corneas. Fatty acid profiles of central button normal and Tangier cornea by gas chromatography are shown in table 2 . The major fatty acid residues were stearate/ oleate/palmitate $\mathrm{C} 18 \cdot 0 / 18 \cdot 1 / 16 \cdot 0$. Thus, the proportion of cholesterol as ester and other component proportions were similar to those reported for Tangier liver ${ }^{17}$ and within the range previously reported for age matched normal 

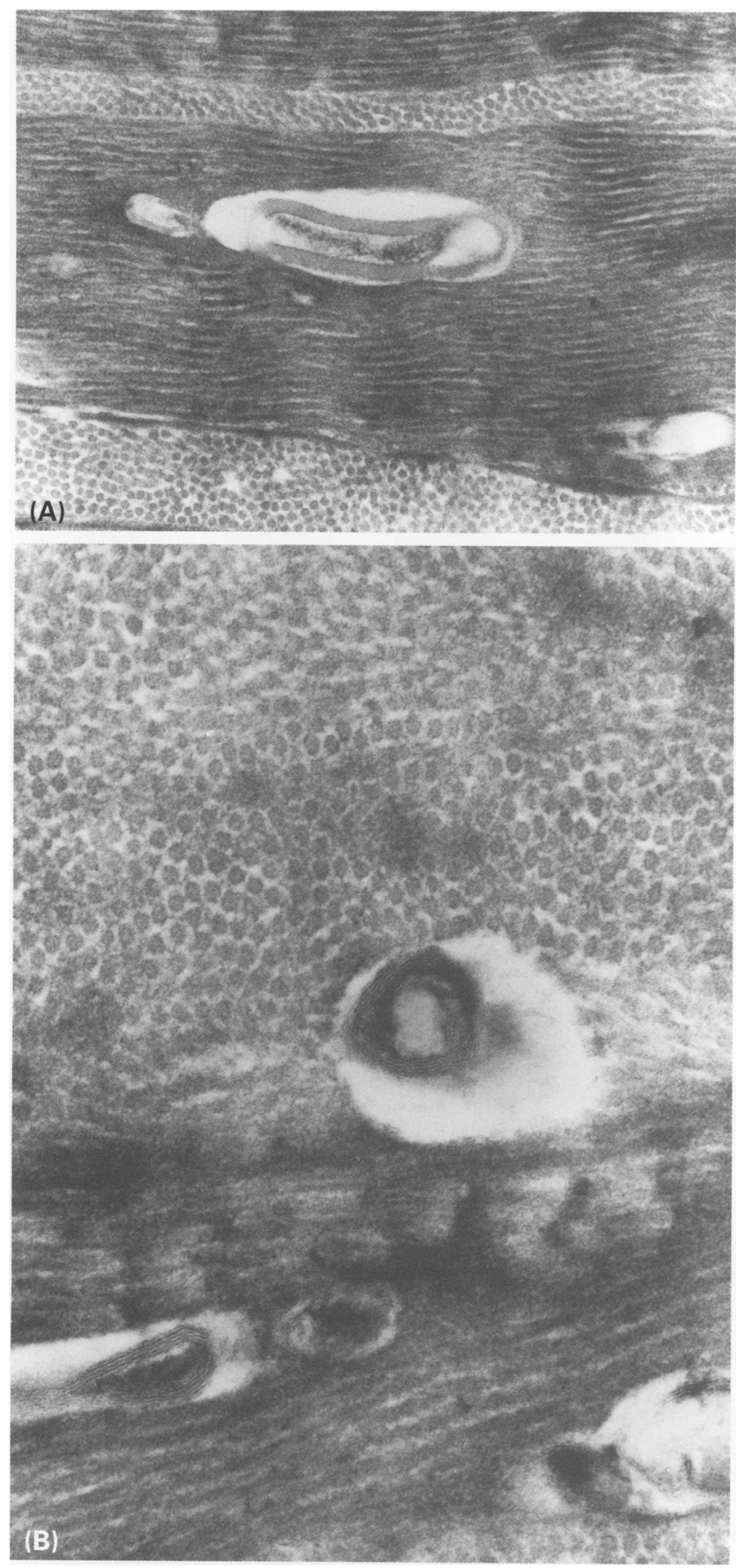

Figure 2 Appearance of Tangier corneal stroma on transmission electron microscopy, showing many membranous lamellar bodies. Magnification $(A) \times 92400,(B) \times 140000$.

cornea, ${ }^{15}$ and for the reference cornea as internal standard except for minor enrichment with $\mathrm{C} 18 \cdot 2$ residues.

DIFFERENTIAL SCANNING CALORIMETRY

Profiles for normal and Tangier corneal material, and for non-Tangier peripheral corneo-
Table 2 Fatty acid profiles of total lipid extracts from Tangier central cornea and control arcus cornea as determined by gas-liquid chromatography

\begin{tabular}{lll}
\hline Fatty acid $(\mu \mathrm{g} / \mathrm{mg})$ & Tangier cornea & Arcus cornea \\
\hline C16.0 & 1.97 & 1.04 \\
C16.1 & 0.69 & 0.37 \\
C18.0 & 18.11 & 0.23 \\
C18.2 & 2.71 & 1.14 \\
C20.0 & 0.78 & 1.40 \\
C20.1 & 0.35 & Not detected \\
\hline
\end{tabular}

scleral ring with heavy corneal arcus are shown in fig 3.

In summary, normal cornea without evident macroscopic arcus or other lipid infiltration showed one major transition, peak temperature $29^{\circ} \mathrm{C}$. Normal cornea with heavy corneal arcus showed several distinct transitions over the temperature range studied. Tangier central cornea showed a broad bimodal major peak with transitions mainly in the range $25-33^{\circ} \mathrm{C}$, extending above that of normal cornea and without the complexity of those seen with cornea with heavy arcus involvement. Profiles on cooling from $42^{\circ} \mathrm{C}$ to $15^{\circ} \mathrm{C}$ are also shown for each sample. No phase transitions were detected, showing that in the time scale of these experiments the lipid melting and related organisational changes were not reversible.

\section{Discussion}

This direct analysis has confirmed that corneal opacification in Tangier disease represents lipid accumulation, as can occur at other sites. Tangier cornea is enriched with lamellar bodies, phospholipid, and with cholesterol predominantly in ester form, in contrast to the accumulations in cornea in familial LCAT deficiency and in Fish-eye disease, in which processes of cholesterol esterification are impaired. The fundamental defect in Tangier disease is not yet defined but does not apparently primarily involve apo A-I, which is of normal sequence but expressed in plasma at very low levels and in immature form. ${ }^{12}$ This and the variable but relative freedom from premature coronary heart disease for such major deficiency of circulating HDL also shown with our patient $^{1819}$ is consistent with some degree of cholesterol transport without impaired esterification, either through other routes or through rapid turnover of HDL. The fatty acid composition of total lipid extracts was also broadly similar to that previously reported for normal cornea, ${ }^{17}$ consistent with active metabolism by cornea of locally insudated vascular lipoproteins as with normal cornea. The processes of cholesterol transfer from cells are plainly impaired, ${ }^{5}$ but patterns of lipid accumulation and their clinical consequences may also depend on further influences including relations with local temperature. Thermal transitions (related to fatty acid composition ${ }^{12}$ ) of storage lipids of spleen and liver in Tangier disease showed a broad peak extending above ambient temperature ${ }^{17}$ : transitions were also reversible both in tissue samples and in lipid droplets prepared from homogenised spleen. ${ }^{17}$ Thermal 

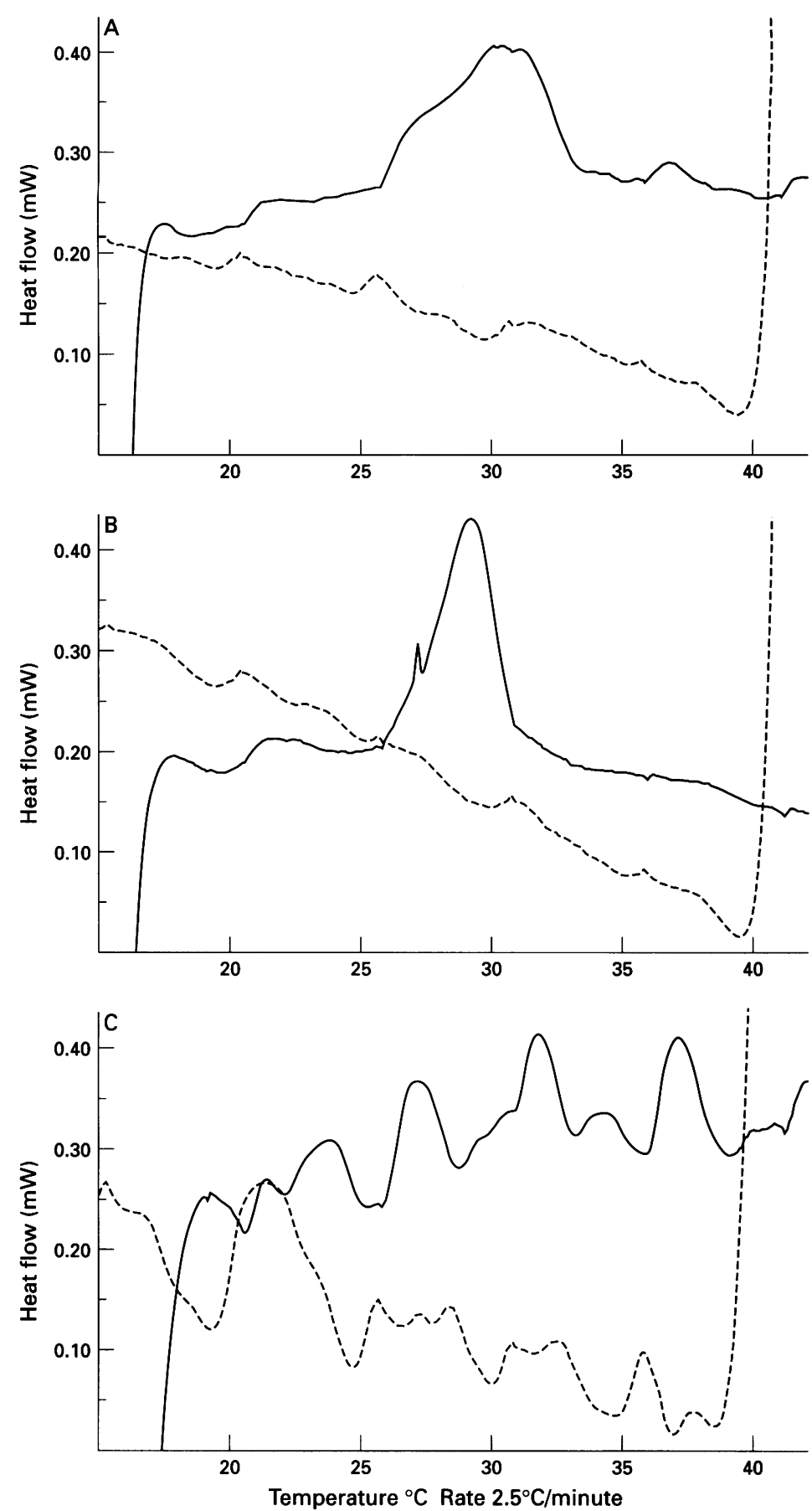

Figure 3 Thermotropic behaviour of corneal samples investigated by differential scanning calorimetry. Samples were scanned using a Perkin Elmer 7 Series Thermal Analysis System over the range $15-42^{\circ} \mathrm{C}$, rate $2.5^{\circ} \mathrm{C} /$ minute. In each case, ascending profiles are shown by the upper (continuous) trace, and reverse profiles on cooling as the lower (broken line) trace. The samples are (A) Tangier corneal button, (B) normal central cornea and (C) normal peripheral cornea with heavy arcus. Normal cornea without arcus showed one major transition, peak temperature $29^{\circ} \mathrm{C}$. Normal cornea with heavy corneal arcus showed several distinct transitions over the range studied. In comparison with normal cornea Tangier central cormea showed a wide bimodal major peak with transitions shifted upwards into the range $25-33^{\circ} \mathrm{C}$. For all samples, the profiles were not consistent when repeated, suggesting that interactions between lipids and with structural elements of cornea were disturbed by temperature cycling over the $15-42^{\circ} \mathrm{C}$ range to which samples were exposed.

transitions were irreversible in all corneal samples (unexpected), but the excess corneal lipid was extracellular, lipid thermotropic behaviour is also modulated by interaction between lipid species and with protein, ${ }^{13}$ and the responses of whole intact tissues as determined here may be the key aspect. Corneas from our patient were obtained late in life, by which time lipid distribution in the cornea had apparently become more generalised, and with the additional and potentially locally confounding complication of keratitis. Also, very little material was retrieved. The Tangier cornea transitions were in the ranges $25-37^{\circ} \mathrm{C}$, peak $30-33^{\circ} \mathrm{C}$, significantly above those for cornea without macroscopic excess lipid accumulation and which probably represent normal corneal membranes, and overlapping with but generally below those seen with cornea with heavy arcus involvement, and those previously reported for xanthelasma. ${ }^{20}$ This broader peak extending to higher temperature with Tangier cornea is consistent with a temperature/lipid composition relation underpinning the effects of the basic Tangier disease on the corneal lipid accumulation, with lipid trapped in a more structured phase limiting remobilisation. The consistency of these various observations also emphasises the potential influence of lipid thermal behaviour on accumulation and mobilisation of lipids in pathological processes in general, ${ }^{121315}$ beyond the exotic expression of Tangier disease.

1 Schaefer EJ. Clinical, biochemical, and genetic features in familial disorders of high density lipoprotein deficiency. Arteriosclerosis 1984;4:303-22.

2 Schmitz G, Fischer H, Beuck M, Hoecker K-P, Robenek H. Dysregulation of lipid metabolism in Tangier monocytederived macrophages. Arteriosclerosis 1990;10:1010-19.

3 Robenek H, Schmitz G. Abnormal processing of Golgi elements and lysosomes in Tangier disease. Arterioscler Thromb 1991;11:1007-20.

4 Walter M, Gerdes U, Seedorf U, Assmann G. The high density lipoprotein and A-I-induced mobilisation of cellular cholesterol is impaired in fibroblasts from Tangier disease subjects. Biochem Biophys Res Commum 1994;205: $850-6$.

5 Remaley AT, Stonik JA, Schumacher K, Hoeg JM, Brewer HB. Defective phospholipid efflux from Tangier disease fibroblasts (abstract). Cinculation 1995;92:556.

6 Winder AF, Borysiewicz LK. Corneal opacification and familial disorders affecting plasma high-density lipoprotein. Birth Defects 1982;18:433-40.

7 protein. Birth Defects 1982;18:433-40.

8 Winder AF, Garner A, Sheraidah GAK, Barry P. Familial Winder AF, Garner A, Sheraidah GAK, Barry P. Familial lecithin:cholesterol acyltransferase deficiency:
chemistry of the cornea. $\mathcal{f}$ Lipid Res 1985;26:283-7.

9 Spaeth GL. Ocular manifestations of the lipidoses. In: Tasman W, ed. Retinal diseases in children. New York: Harper and Row, 1971:127-206.

10 Pressly TA, Scott WJ, Ide CH, Winkler A, Reams G. Ocular complications of Tangier disease. Am 7 Med 1987;83: 991-4.

11 Fielder AR, Winder AF, Cooke ED, Bowcock SA. Arcus senilis and corneal temperature in man. In: The cornea in health and disease. VI Congress of the European Society of Ophthalmology. London: Royal Society of Medicine and Academic Press, 1981:101:22-6.

12 Davis GJ, Porter RS, Steiner JW, Small DM. Thermal transitions of cholesterol esters of $\mathrm{C18}$ aliphatic acids. Molecular Crystals and Liquid Crystals 1970;10:331-6.

13 Deckelbaum RJ, Shipley GG, Small DM. Structure and interactions of lipids in human plasma low density lipoproteins. $\widetilde{f}$ Biol Chem 1977;252:744-54.

14 Frohlich J, Fong B, Julien P, Despres J-P, Angel A, Hayden $\mathrm{M}$, et al. Interaction of high density lipoprotein with adipocytes in a new patient with Tangier disease. Clin Invest Med 1987;10:377-82.

15 Sheraidah GAK, Winder AF, Fielder AR. Lipid-protein constituents of human corneal arcus. Atherosclerosis 1981; 40:91-8.

16 Schmitz G, Assmann G, Bowyer, DE. A quantitative densitometric method for the rapid separation and quantitation of the major tissue and lipoprotein lipids by highperformance thin-layer chromatography. $\not$ Chromatog performance thin-

17 Katz SJ, Small DM, Brook JG, Lees RS. The storage lipids in Tangier disease. A physical chemical study. $\mathcal{F}$ Clin Invest 1975;59:1045-54

18 Mautner SL, Sanchez JA, Rader DJ, Mautner C, Ferrans VJ, Fredrickson DS, et al. The heart in Tangier disease. Severe coronary atherosclerosis with near absence of highdensity lipoprotein cholesterol. Am f Clin Pathol 1992;98: 191-8

19 Serfaty-Lacrosniere C, Civiera F, Lanzberg A, Isaia P, Berg $\mathrm{J}$, Janus ED, et al. Homozygous Tangier disease and cardiovascular disease. Atherosclerosis 1994;107:85-98.

20 Winder AF, Bruckdorfer KR, Fielder AR. Thermal transition studies of a mature xanthelasma by differential scanning calorimetry. Clin Chim Acta 1985;151:253-7. 